\title{
PEP-1-GSTpi protein enhanced hippocampal neuronal cell survival after oxidative damage
}

\author{
Eun Jeong Sohn ${ }^{1, \#}$, Min Jea Shin ${ }^{1, \#}$, Dae Won Kim ${ }^{2, *}$, Ora Son ${ }^{1}$, Hyo Sang Jo ${ }^{1}$, Su Bin Cho ${ }^{1}$, Jung Hwan Park ${ }^{1}$, \\ Chi Hern Lee ${ }^{1}$,Eun Ji Yeo ${ }^{1}$, Yeon Joo Choi ${ }^{1}$, Yeon Hee Yu ${ }^{3}$, Duk-Soo Kim ${ }^{3}$, Sung-Woo Cho ${ }^{4}$, Oh Shin Kwon ${ }^{5}$, \\ Yong-Jun Cho ${ }^{6}$, Jinseu Park ${ }^{1}$, Won Sik Eum ${ }^{1, *}$ E Soo Young Choi ${ }^{1, *}$ \\ ${ }^{1}$ Department of Biomedical Science and Research Institute of Bioscience and Biotechnology, Hallym University, Chunchon 24252, \\ ${ }^{2}$ Department of Biochemistry and Molecular Biology, Research Institute of Oral Sciences, College of Dentistry, Gangnung-Wonju National \\ University, Gangneung 25457, ${ }^{3}$ Department of Anatomy, College of Medicine, Soonchunhyang University, Cheonan 31538, ${ }^{4}$ Department of \\ Biochemistry and Molecular Biology, University of Ulsan College of Medicine, Seoul 05505, ${ }^{5}$ School of Life Sciences, College of Natural \\ Sciences, Kyungpook National University, Daegu 41566, ${ }^{6}$ Department of Neurosurgery, Hallym University Medical Center, Chuncheon \\ 24253, Korea
}

Reactive oxygen species generated under oxidative stress are involved in neuronal diseases, including ischemia. Glutathione S-transferase pi (GSTpi) is a member of the GST family and is known to play important roles in cell survival. We investigated the effect of GSTpi against oxidative stress-induced hippocampal HT-22 cell death, and its effects in an animal model of ischemic injury, using a cell-permeable PEP-1-GSTpi protein. PEP-1-GSTpi was transduced into HT-22 cells and significantly protected against $\mathrm{H}_{2} \mathrm{O}_{2}$-treated cell death by reducing the intracellular toxicity and regulating the signal pathways, including MAPK, Akt, Bax, and Bcl-2. PEP-1-GSTpi transduced into the hippocampus in animal brains, and markedly protected against neuronal cell death in an ischemic injury animal model. These results indicate that PEP-1-GSTpi acts as a regulator or an antioxidant to protect against oxidative stressinduced cell death. Our study suggests that PEP-1-GSTpi may have potential as a therapeutic agent for the treatment of ischemia and a variety of oxidative stress-related neuronal diseases. [BMB Reports 2016; 49(7): 382-387]

\section{INTRODUCTION}

Glutathione S-transferase (GST) exists in all cells of higher

*Corresponding authors. Soo Young Choi, Tel: +82-33-248-2112; Fax: +82-33-241-1463; E-mail: sychoi@hallym.ac.kr, Won Sik Eum, Tel: +82-33-248-2112; Fax: +82-33-241-1463; E-mail: wseum@ hallym.ac.kr

${ }^{\text {"}}$ These authors contributed equally to this work.

http://dx.doi.org/10.5483/BMBRep.2016.49.7.048

Received 8 March 2016, Revised 28 March 2016, Accepted 4 April 2016

Keywords: Apoptotic signals, Ischemia, Oxidative stress, PEP-1GSTpi, Protein therapy organisms and is known as a reactive oxygen species (ROS) scavenger and detoxifying protein. GST has been identified as a member of the multigene family of isozymes which exist in three forms in accordance with substrate specificity; these include the basic hepatic form (alpha), near neutral hepatic form (mu), and acidic placental form (pi) (1-4). Several studies have demonstrated that GSTpi is expressed in the kidney, the placenta, and the fetal liver, as well as being highly expressed in several human cancers including liver, colon, and stomach cancer. Overexpressed GSTpi increased the resistance to anticancer drugs, and is recognized as a tumor marker (5-7). However, other studies have shown that GSTpi plays an important role in the cell survival against carcinogens, antineoplastons, and cytotoxic effects. In addition, GSTpi is known to regulate cellular signaling pathways, including c-Jun $\mathrm{NH} 2$-terminal kinases (JNKs) and inhibits tumor necrosis factor alpha (TNF $\alpha$ )-induced apoptosis (8-12).

Oxidative stress, which induces the production of ROS, is one of the major risk factors in neuronal diseases. It is well known that ROS is produced naturally during cell metabolism, and excessive ROS production significantly contributes to neuronal damage. Thus, excessive ROS production is considered a hallmark of various neuronal diseases, including ischemia (13-16). In addition, several studies have demonstrated that excessive ROS levels are markedly increased during ischemic injury, and eventually lead to neuronal cell death via apoptotic signal pathways (17-19). However, little is known about the effects of GSTpi protein against oxidative stress-induced hippocampal neuronal cell death and ischemic injury.

To develop therapeutic agents as drugs to treat neuronal diseases, efficient transduction methods are important, since the transduction efficiency is restricted by low cell membrane permeability in the application of therapeutic agents. However, many studies have shown that therapeutic proteins transduce into the cells and provide protective effects against various diseases using protein transduction domains (PTDs) or 
cell-penetrating peptides (CPPs) as delivery systems (20-23). Our previous studies have demonstrated that PTD fused proteins transduce into cells or tissues and significantly increase the cell survival against oxidative stress-induced neuronal cell death, as well as attenuate Parkinson's disease and ischemic injury in an animal model (24-26).

In this study, we examined the potentially protective effects of PEP-1-GSTpi in hippocampal HT-22 cells and in an animal model of ischemia. PEP-1-GSTpi transduced into both HT-22 cells and animal brain cells, where it significantly protected against hippocampal neuronal cell death induced by oxidative stress. These results lead us to suggest that PEP-1-GSTpi may be a therapeutic agent for treatment of ischemic injury and oxidative stress related disorders.

\section{RESULTS AND DISCUSSION}

\section{Purified PEP-1-GSTpi protein was transduced into the HT-22 cells}

GSTpi protein is known to play a crucial role in protecting against oxidative stress-induced cell death, and has antioxidant and anti-inflammatory functions $(27,28)$. Although GSTpi has been shown to have beneficial roles in these physiological processes, its role in ischemic injury remains unclear. To examine the effects of GSTpi protein against oxidative stress-induced HT-22 cell death and in an animal model of ischemia, we generated a PEP-1-GSTpi protein with the ability to transduce into cells. As shown in Fig. 1A, cell permeable PEP-1-GSTpi and control GSTpi proteins were prepared; these were purified using a $\mathrm{Ni}^{2+}$-nitrilotriacetic acid Sepharose affinity column and PD-10 column chromatography. SDS-PAGE and Western blot analysis were used to confirm the purified proteins.

To validate the permeability of PEP-1-GSTpi into HT-22 cell, we treated cells with various concentrations (1-14 $\mu \mathrm{M})$ of PEP-1-GSTpi or control GSTpi proteins for $1 \mathrm{~h}$; evaluation was also done at various times (10-60 min) of treatment with a consistent concentration $(14 \mu \mathrm{M})$ of PEP-1-GSTpi or control GSTpi proteins. The resultant cells were analyzed by Western blotting. We found that the PEP-1-GSTpi protein was transduced into HT-22 cells in a dose- and time-dependent manner. Conversely, control GSTpi protein demonstrated no such transduction (Fig. 1B). In addition, we confirmed the intracellular stability and transduction using Western blotting and double fluorescence staining. As shown in Figs. 1C and Supplementary Fig. 1, PEP-1-GSTpi protein was transduced into HT-22 cells and remained stable within the cells for $48 \mathrm{~h}$. Although transduction mechanisms are still not fully understood, various hypothesis of PTD transduction mechanism has been suggested by different routes such as PTD types or concentrations, endocytosis, direct and adaptive transduction (29). In addition, transduction efficiency of PTD fusion protein depends on several factors, including PTD types, protein size, and cell types $(21,22,30)$. Further studies are needed to determine the exact transduction mechanism of the PTD fusion protein. In this study, we demonstrated that PEP-1-GSTpi protein was able to be efficiently transduced into HT-22 cells.

\section{PEP-1-GSTpi inhibited the intracellular toxicity from oxidative stress}

Hydrogen peroxide $\left(\mathrm{H}_{2} \mathrm{O}_{2}\right)$ is known to be present in low concentrations under normal physiological conditions, but at markedly increased levels in cases of brain injury, including ischemia and spinal cord injury $(31,32)$. Excessive $\mathrm{H}_{2} \mathrm{O}_{2}$ levels are known to significantly contribute to neuronal cell death. To determine whether PEP-1-GSTpi protein inhibits cellular toxicities induced by $\mathrm{H}_{2} \mathrm{O}_{2}$, we examined cell viability
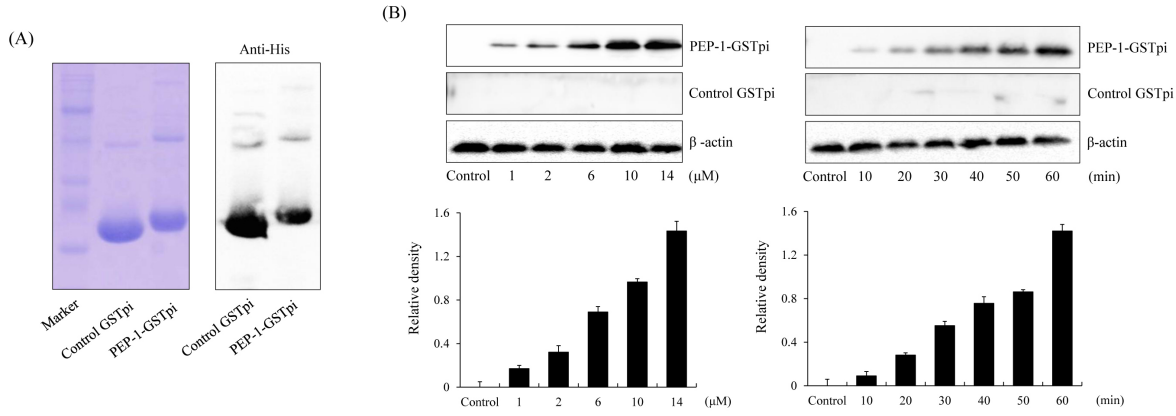

(C)
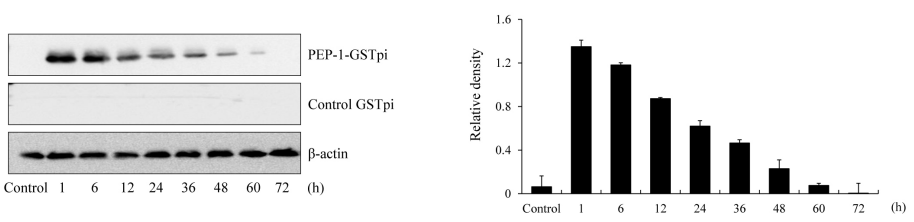

Fig. 1. Purified PEP-1-GSTpi protein transduction into HT-22 cells. (A) Purified PEP-1-GSTpi proteins were identified by $12 \%$ SDS-PAGE and Western blot analysis using an anti-His antibody. (B) Transduction of PEP-1GSTpi proteins into HT-22 cells. Cells were treated with PEP-1-GSTpi proteins (1-14 $\mu \mathrm{M})$ for $1 \mathrm{~h}$, or cells were treated with PEP-1-GSTpi proteins $(14 \mu \mathrm{M})$ for 10-60 min (C) The stability of transduced PEP-1-GSTpi proteins into HT-22 cell. After PEP-1-GSTpi proteins (14 $\mu \mathrm{M})$ transduced into the HT-22 cells, the cells were incubated for 1-72 $\mathrm{h}$ and analyzed by Western blotting; the band intensity was measured by densitometer. 
(A)

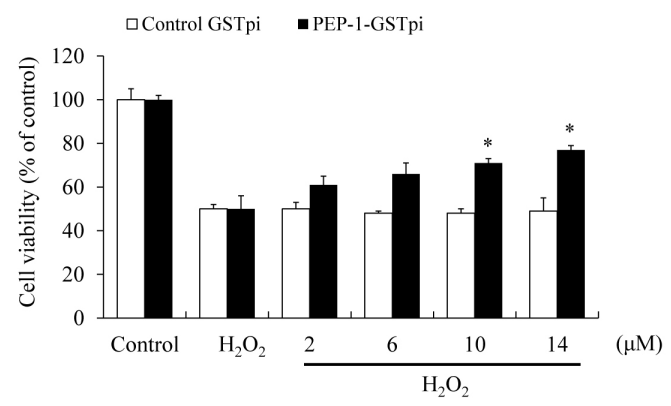

(B)
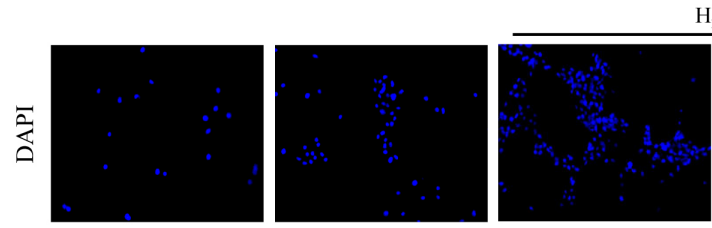

$\mathrm{H}_{2} \mathrm{O}_{2}$
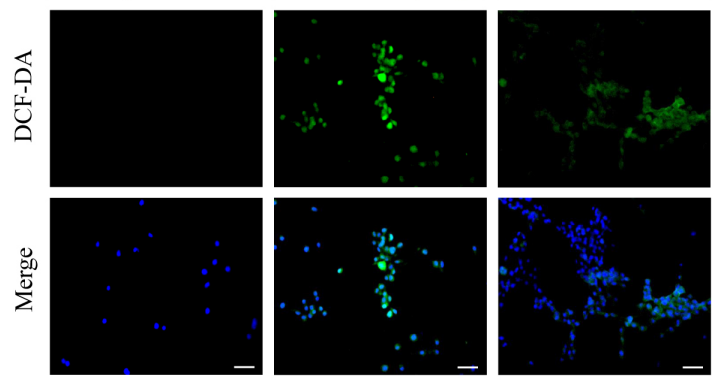

Control

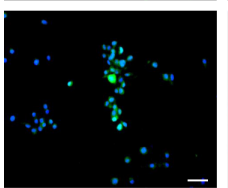

$\mathrm{H}_{2} \mathrm{O}_{2}$

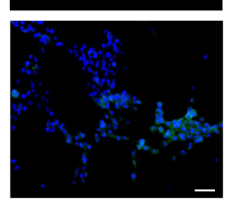

Control GSTpi
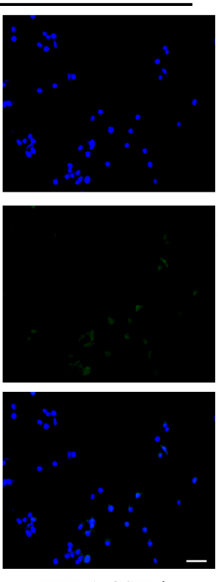

PEP-1-GSTpi
Fig. 2. Effects of PEP-1-GSTpi protein against $\mathrm{H}_{2} \mathrm{O}_{2}$-induced cellular toxicities. After pretreatment with $14 \mu \mathrm{M}$ of PEP1-GSTpi protein for $1 \mathrm{~h}$ into HT-22 cells, (A) cell viability was determined by WST-1 assay. HT-22 cells were pretreated with PEP-1-GSTpi protein (14 $\mu \mathrm{M})$ for $1 \mathrm{~h}$, following which they were exposed to $\mathrm{H}_{2} \mathrm{O}_{2}(0.5 \mathrm{mM})$ for 20 min. (B) intracellular ROS levels were detected by DCF-DA staining. Scale bar $=20 \mu \mathrm{m} . * \mathrm{P}<0.01$, compared with $\mathrm{H}_{2} \mathrm{O}_{2}$-treated cells. and intracellular ROS production in HT-22 cells exposed to $\mathrm{H}_{2} \mathrm{O}_{2}$. WST-1 assay showed that $\mathrm{H}_{2} \mathrm{O}_{2}$ treatment decreased the cell survival from $100 \%$ to $50 \%$, whereas transduced PEP-1-GSTpi dose-dependently inhibited the $\mathrm{H}_{2} \mathrm{O}_{2}$-induced cell death by up to $77 \%$ (Fig. 2A). We next performed DCF-DA staining to examine the effect of PEP-1-GSTpi protein against intracellular ROS production. As shown in Fig. 2B, $\mathrm{H}_{2} \mathrm{O}_{2}$-induced intracellular $\mathrm{ROS}$ production levels were markedly increased. In contrast, increased intracellular ROS production levels were significantly decreased by transduced PEP-1-GSTpi protein. Several studies have demonstrated that excessive $\mathrm{H}_{2} \mathrm{O}_{2}$ is associated with many central nervous system disorders, including ischemia and cancer. Also, increased GSTpi protein inhibited cell death via decrease in the intracellular $\mathrm{H}_{2} \mathrm{O}_{2}$ levels $(33,34)$. Consistent with other studies, our results show that transduced PEP-1-GSTpi protein protected against the oxidative stress-induced cell death.

PEP-1-GSTpi protein inhibited apoptotic signaling pathways We further confirmed whether transduced PEP-1-GSTpi affects the oxidative stress-induced apoptotic signaling pathways. The mitogen-activated protein kinase (MAPK) signal pathway is known to be activated by a variety of external stimuli (including ROS), and is involved in apoptosis during ischemic injury. Akt is also highly involved in neuron survival in ischemia (35-37). As shown in Fig. 3A, phosphorylated p38, JNK, and Akt expression levels were increased in the $\mathrm{H}_{2} \mathrm{O}_{2}$ treated cells. PEP-1-GSTpi markedly decreased the phosphorylated p38, JNK, and Akt expression levels. In contrast, control GSTpi protein did not affect these signaling pathways (data not shown). We also examined the effects of PEP-1-GSTpi protein on the $\mathrm{Bax}, \mathrm{Bcl}-2$, and mitochondria membrane potential dysfunction which are all highly associated with ROS and cell survival (38-40). PEP-1-GSTpi protein significantly increased the expression levels of $\mathrm{Bcl}-2$, whereas Bax expression levels were decreased in $\mathrm{H}_{2} \mathrm{O}_{2}$ treated cells (Fig. 3B). Also, PEP-1-GSTpi protein significantly inhibited mitochondria membrane potential dysfunction induced by oxidative stress (Supplementary Fig. 2). These results indicate that PEP-1-GSTpi protein increased the cell survival after oxidative stress by regulating apoptotic signaling pathways. However, further research is necessary to provide a better understanding of the mechanism or mechanisms involved. 
(A)
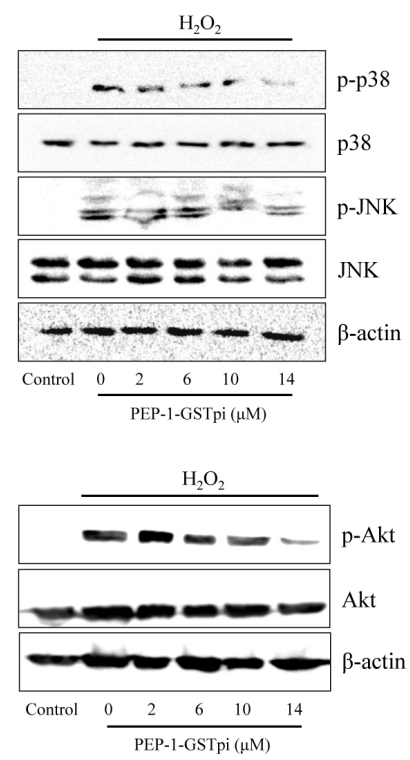

(B)

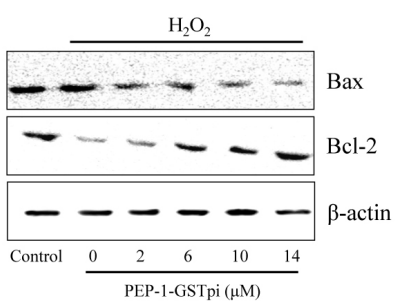

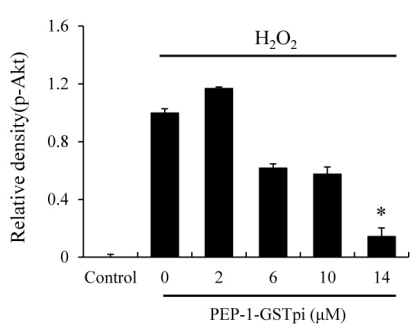
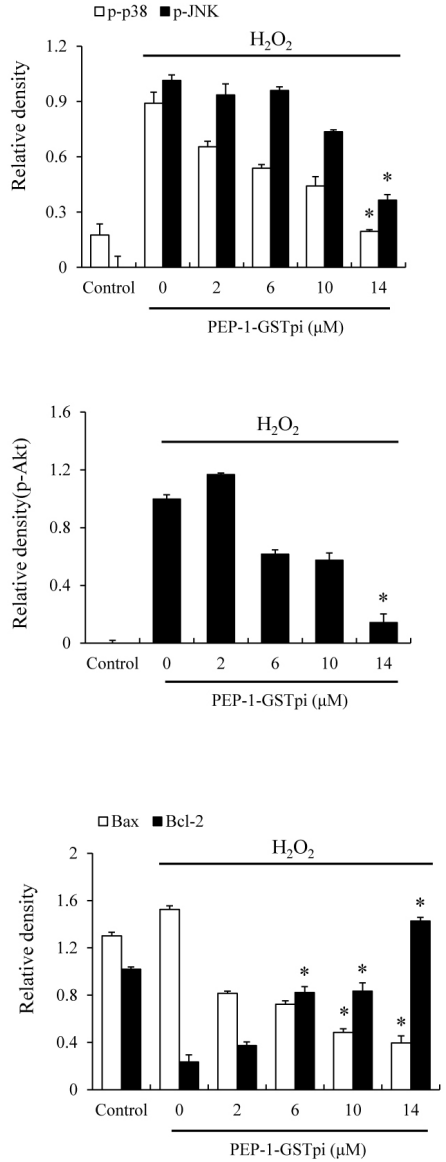

Fig. 3. Effects of PEP-1-GSTpi protein on $\mathrm{H}_{2} \mathrm{O}_{2}$-induced cellular signaling pathways and mitochondrial membrane potential in HT-22 cells. After treatment of HT-22 cells with $14 \mu \mathrm{M}$ of PEP-1-GSTpi proteins, the cells were treated with $\mathrm{H}_{2} \mathrm{O}_{2}$ $(0.5 \mathrm{mM})$ for $1 \mathrm{~h}$ (p38 and JNK), $40 \mathrm{~min}$ (Akt), and $6 \mathrm{~h} \mathrm{(Bcl-2} \mathrm{and} \mathrm{Bax),}$ respectively. Subsequently, (A) phosphorylated p38, JNK, and Akt levels and (B) $\mathrm{BCl}-2$ and $\mathrm{Bax}$ levels were measured by Western blot analysis; the band intensity were measured by densitometer. $* \mathrm{P}<0.01$, compared with $\mathrm{H}_{2} \mathrm{O}_{2-}$ treated cells.

\section{PEP-1-GSTpi attenuated ischemic injury in an animal model} Several studies have demonstrated that PTD fusion protein is efficiently transduced into the brain crossing the blood-brain barrier (BBB). This transduction has been used to enhance the uptake of therapeutic proteins in various animal models of neurodegenerative diseases $(21-26,29,30)$. Thus, we first examined whether the PEP-1-GSTpi protein transduces into the mice brain crossing the BBB in an ischemic injury animal model. As shown in Fig. 4A, GSTpi protein levels were markedly increased in the CA1 region of the brain in the PEP-1-GSTpi-treated mice. In contrast, GSTpi protein was not detected in the control GSTpi-treated mice. In addition, post ischemic injury neuronal cell survival in the hippocampal CA1 region was markedly increased after treatment with PEP-1-GSTpi protein, suggesting that the PEP-1-GSTpi protein was efficiently transduced into the animal brain and protected against neuronal cell death.

Next, we conducted immunohistochemistry experiments to better understand the protective effects of PEP-1-GSTpi protein in an animal model of ischemic injury. As shown in Fig. 4B, neuronal cell death significantly increased in the vehicletreated mice. PEP-1-GSTpi protein drastically increased the neuronal cell survival. However, there were no differences between the control GSTpi-treated mice and the vehicletreated mice. Also, PEP-1-GSTpi protein inhibited the activation of astrocytes and microglial cells. Other studies have demonstrated that GSTpi protein protected against oxidative stress-induced SH-SY5Y cell death. Also, GSTpi protein provided protection against dopaminergic neuronal cell death in MPTP-induced PD mouse models $(41,42)$. In previous studies, we have demonstrated that the PTD fused therapeutic protein crossed the BBB and significantly inhibited against ischemic injury (24-26).

In conclusion, we have shown that PEP-1-GSTpi protein was transduced into both HT-22 cells and mice brain, and it significantly protected against oxidative stress-induced cell death and ischemic injury, respectively. Based on these results, we suggest that PEP-1-GSTpi protein is a potential therapeutic agent for ischemia. 
(A)

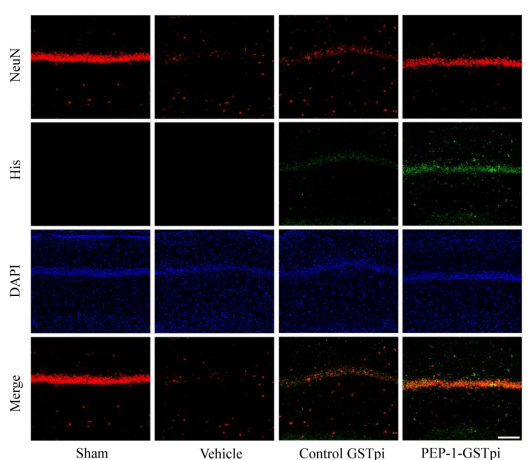

(B)

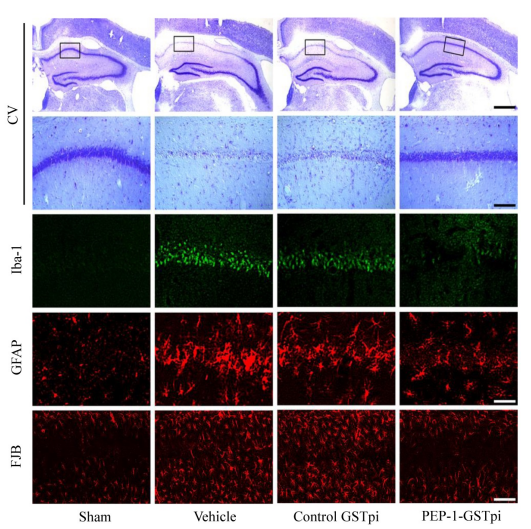

Fig. 4. Protective effect of PEP-1-GSTpi protein in ischemic injury animal model. Gerbils were treated with a single injection of PEP-1-GSTpi protein (2 mg/kg) or control GSTpi protein. After 7 days, brain tissue was collected and immunohistochemistry performed. (A) Transduction of PEP-1-GSTpi into the gerbil brain and ischemic neuronal damage was determined using anti-His antibody and NeuN immunohistochemistry. Scale bar $=50 \mu \mathrm{m}$. (B) Protective effect of PEP-1-GSTpi protein on ischemia was confirmed using Cresyl violet, Iba-1, GFAP, and FJB immunostaining. Scale bar $=400 \mu \mathrm{m}, 50 \mu \mathrm{m}$, and $25 \mu \mathrm{m}$.

\section{MATERIALS AND METHODS}

See supplementary information for this data.

\section{ACKNOWLEDGEMENTS}

This work was supported by a Priority Research Centers Program grant (NRF-2009-0093812) through the National Research Foundation of Korea funded by the Ministry of Science, ICT \& Future Planning in the Republic Korea and in part by a grant from Hallym University Specialization Fund (HRF-S-13). Also, this study was supported by the Basic Science Research Program through the National Research Foundation of Korea funded by the Ministry of Education (2015R1D1A3A01015668), and in part by BioGreen21 Program (PJ01121401) of Rural Development Administration.

\section{REFERENCES}

1. Udomsinprasert $\mathrm{R}$, Pongjaroenkit $\mathrm{S}$, Wongsantichon $\mathrm{J}$ et al (2005) Identification, characterization and structure of a new delta class glutathione transferase isoenzyme. Biochem J 388, 763-771

2. Sheehan D, Meade G, Foley VM and Dowd CA (2001) Structure, function and evolution of glutathione transferases: implications for classification of non-mammalian members of an ancient enzyme superfamily. Biochem J 36, 1-16

3. Raza H (2011) Dual localization of glutathione S-transferase in the cytosol and mitochondria: implications in oxidative stress, toxicity and disease. FEBS J 278, 4243-4251

4. Atkinson HJ and Babbitt PC (2009) Glutathione transferases are structural and functional outliers in the thioredoxin fold. Biochemistry 48, 11108-11116

5. Harrison DJ, Kharbanda R, Cunningham DS, McLellan LI and Hayes JD (1989) Distribution of glutathione S-transferase isoenzymes in human kidney: basis for possible markers of renal injury. J Clin Pathol 42, 624-628

6. Landi S (2000) Mammalian class theta GST and differential susceptibility to carcinogens: a review. Mutat Res 463, 247-283

7. Townsend DM and Tew KD (2003) The role of glutathione-S-transferase in anti-cancer drug resistance. Oncogene 22, 7369-7375

8. Mari M, Morales A, Colell A, Garcia-Ruiz C and Fernandez-Checa JC (2009) Mitochondrial glutathione, a key survival antioxidant. Antioxid Redox Signal 11, 2685-2700

9. Tew KD and Ronai Z (1999) GST function in drug and stress response. Drug Resist Updat 2, 143-147

10. Laborde E (2010) Glutathione transferases as mediators of signaling pathways involved in cell proliferation and cell death. Cell Death Differ 17, 1373-1380

11. Thevenin AF, Zony CL, Bahnson BJ and Colman RF (2011) GSTpi modulates JNK activity through a direct interaction with JNK substrate, ATF2. Protein Sci 20, 834-848

12. $\mathrm{Wu} Y$, Fan $\mathrm{Y}, \mathrm{Xue} B$ et al (2006) Human glutathione S-transferase P1-1 interacts with TRAF2 and regulates TRAF2-ASK1 signals. Oncogene 25, 5787-5800

13. Misra MK, Sarwat M, Bhakuni P et al (2009) Oxidative stress and ischemic myocardial syndromes. Med Sci Monit 15, RA209-RA219

14. Halliwell B (2006) Oxidative stress and neurodegeneration: where are we now? J Neurochem 97, 1634-1658

15. Giorgio M, Trinei M, Migliaccio E and Pelicci PG (2007) Hydrogen peroxide: a metabolic by-product or a common mediator of ageing signals? Nat RevMol Cell Biol 8, 722-728

16. Coyle JT and Puttfarcken P (1993) Oxidative stress, glutamate, and neurodegenerative disorders. Science 262, 689-695

17. Kleikers PW, Wingler K, Hermans JJ et al (2012) NADPH oxidases as a source of oxidative stress and molecular target in ischemia/reperfusion injury. J Mol Med 90, 13911406

18. Moro MA, Almeida A, Bolanos JP and Lizasoain I (2005) 
Mitochondrial respiratory chain and free radical generation in stroke. Free Radic Biol Med 39, 1291-1304

19. Atlante A, Bobba A, Calissano P, Passarella S and Marra E (2003) The apoptosis/necrosis transition in cerebellar granule cells depends on the mutual relationship of the antioxidant and the proteolytic systems which regulate ROS production and cytochrome c release enroute to death. J Neurochem 84, 960-971

20. Jay SM and Lee RT (2013) Protein engineering for cardiovascular therapeutics: untapped potential for cardiac repair. Circ Res 113, 933-943

21. Koren E and Torchilin VP (2012) Cell-penetrating peptides: breaking through to the other side. Trends Mol Med 18, 385-393

22. Gump JM and Dowdy SF (2007) TAT transduction: the molecular mechanism and therapeutic prospects. Trends Mol Med 13, 443-448

23. Brooks NA, Pouniotis DS, Tang CK, Apostolopoulos V and Pietersz GA (2010) Cell penetrating peptides: application in vaccine delivery. Biochim Biophys Acta 1805, 25-34

24. Woo SJ, Shin MJ, Kim DW et al (2015) Effects of low doses of Tat-PIM2 protein against hippocampal neuronal cell survival. J Neurol Sci 358, 226-235

25. Kim MJ, Park M, Kim DW et al (2015) Transduced PEP-1-PON1 proteins regulate microglial activation and dopaminergic neuronal death in a Parkinson's disease model. Biomaterials 64, 45-56

26. Jeong HJ, Yoo DY, Kim DW et al (2014) Neuroprotective effect of PEP-1-peroxiredoxin2 on CA1 regions in the hippocampus against ischemic insult. Biochim Biophys Acta 1840, 2321-2330

27. Luo L, Wang Y, Feng Q et al (2009) Recombinant protein glutathione S-transferases P1 attenuates inflammation in mice. Mol Immunol 46, 848-857

28. Townsend DM, Manevich Y, He L, Hutchens S, Pazoles CJ and Tew KD (2009) Novel role for glutathione S-transferase pi: regulator of protein S-glutathionylation following oxidative and nitrosative stress. J Biol Chem 284, 436-445

29. Ramsey JD and Flynn NH (2015) Cell-penetrating peptides transport therapeutics into cells. Pharmacol Therapeut 154, 78-86

30. Dietz (2010) Cell penetrating peptide technology to delivery chaperones and associated factors in diseases and basic research. Curr Pharm Biotechnol 11, 167-174

31. Lei B, Adachi $N$ and Arai $T$ (1998) Measurement of the extracellular $\mathrm{H}_{2} \mathrm{O}_{2}$ in the brain by microdialysis. Brain Res Brain Res Protoc 3, 33-36

32. Liu D, Liu J and Wen J (1999) Elevation of hydrogen peroxide after spinal cord injury detected by using the
Fenton reaction. Free Radic Biol Med 27, 478-482

33. Zhou L, Jing Y, Styblo M, Chen Z and Waxman S (2005) Glutathion-S-transferase $\pi$ inhibits $\mathrm{As}_{2} \mathrm{O}_{3}$-induced apoptosis in lymphoma cells: involvement of hydrogen peroxided catabolism. Blood 105, 1198-1203

34. Ohashi M, Hirano T, Watanabe K et al (2016) Hydrogen peroxide modulates synaptic transmission in ventral horn neurons of the rat spinal cord. J Physiol 594, 115-134

35. Prasad SS, Russell M and Nowakowska M (2011) Neuroprotection induced in vitro by ischemic preconditioning and postconditioning: modulation of apoptosis and PI3K-Akt pathways. J Mol Neurosci 43, 428-442

36. Adler V, Yin Z and Fuchs SY (1999) Regulation of JNK signaling by GSTpi. EMBO J 18, 1321-1334

37. Kwon SH, Hong SI, Kim JA et al (2011) The neuroprotective effects of Lonicera japonica THUNB. against hydrogen peroxide-induced apoptosis via phosphorylation of MAPKs and PI3K/Akt in SH-SY5Y cells. Food Chem Toxicol 49,1011-1019

38. Higgins GC, Beart PM, Shin YS, Chen MJ, Cheung NS and Nagley P (2010) Oxidative stress: emerging mitochondrial and cellular themes and variations in neuronal injury. J Alzheimers Dis 20, 453-473

39. Choi WS, Canzoniero LM, Sensi SL et al (1999) Characterization of $\mathrm{MPP}^{+}$-induced cell death in a dopaminergic neuronal cell line : role of macromolecule synthesis, cytosolic calcium, caspase, and Bcl-2-related proteins. Exp Neurol 159, 274-282

40. Fuenzalida K, Quintanilla R, Ramos P et al (2007) Peroxisome proliferator-activated receptor gamma up-regulates the $\mathrm{Bcl}-2$ anti-apoptotic protein in neurons and induces apoptosis. J Biol Chem 282, 37006-37015

41. Castro-Caldas M, Milagre I, Rodrigues E and Gama MJ (2009) Glutathion S-transferase pi regulates UV-induced JNK signaling in SH-SY5Y neuroblastoma cells. Neurosci Lett 451, 241-245

42. Castro-Caldas M, Nerves-Carvalho A, Peixeiro I, Rodrigues E, Lechner MC and Gama MJ (2009) GSTpi expression in MPTP-induced dopaminergic neurodegeneration of C57BL/6 mouse midbrain and striatum. J Mol Neurosci 38, 114-127

43. Bradford MA (1976) A rapid and sensitive method for the quantification of microgram quantities of protein utilizing the principle of protein-dye binding. Anal Biochem 72, 248-254

44. Kim YN, Jung HY, Eum WS et al (2014) Neuroprotective effects of PEP-1-carbonyl reductase 1 against oxidative stress-induced ischemic neuronal cell damage. Free Radic Biol Med 69, 181-196 